\title{
Median Nerve Location Change Evaluated by Soft Cadaver Dissection According to the Forearm Movement
}

\author{
Cambio de Posición del Nervio Mediano Evaluado Mediante Disección \\ Cadavérica Blanda según el Movimiento del Antebrazo
}

\author{
Seongoh Kwon"; Young Gil Jeong**; Nam Seob Lee**; Seung Yun Han**; \\ Chang Sub Uhm***; Dasom Kim**** ${ }^{*}$ Je-Hun Lee (** $^{*}$
}

KWON, S.; JEONG, Y.; LEE, N. S.; HAN, S. Y.; UHM, C. S.; KIM, D. \& LEE, J. H. Median nerve location change evaluated by soft cadaver dissection according to the forearm movement. Int. J. Morphol., 34(2):759-762, 2016.

SUMMARY: The aim of this study was to examine the change in median nerve location according to forearm movement. Thirty fresh specimens from 15 adult Korean cadavers (10 males and five females; age range, 53-91 years) were examined. We measured the motor entry point according to normal and pronated positions of the forearm. The $\mathrm{x}$ and $\mathrm{y}$ coordinates of the first motor entry point (MEP) in the normal position were $1.6 \pm 0.6 \mathrm{~cm}$ and $2.8 \pm 1.3 \mathrm{~cm}$, respectively. The depth of the MEP was $1.5 \pm 0.3 \mathrm{~cm}$. The $\mathrm{x}$ and $\mathrm{y}$ coordinates of the second MEP were $1.3 \pm 0.3 \mathrm{~cm}$ and $4.7 \pm 1.7 \mathrm{~cm}$, respectively. The depth of the MEP was $1.4 \pm 0.2 \mathrm{~cm}$. The $\mathrm{x}$ and $\mathrm{y}$ coordinates of first MEP with the forearm in the pronated position were $1.9 \pm 0.7 \mathrm{~cm}$ and $2.3 \pm 0.8 \mathrm{~cm}$. respectively. The depth of the MEP was $1.7 \pm 0.4 \mathrm{~cm}$. The $\mathrm{x}$ and $\mathrm{y}$ coordinates of the second MEP were $1.6 \pm 0.7 \mathrm{~cm}$ and $4.4 \pm 1.7 \mathrm{~cm}$, respectively. The depth of the MEP was $1.6 \pm 0.3 \mathrm{~cm}$. The differences in locations according to movement of the nerve branch were $0.3 \mathrm{~cm}$, and depths were $0.2 \mathrm{~cm}$. The pronated position results of this study will be clinically helpful.

KEY WORDS: Anatomy; Median nerve; Forearm movement; Motor entry point; Injection.

\section{INTRODUCTION}

The pronator teres (PT) is a short muscle connecting the ends of the humerus and ulna to the radius and pronates the forearm. Hyperactivity and hypertonicity of the PT is followed by spasticity of the muscle, which interferes with upper extremity function, limits daily activities, and can cause musculoskeletal complications.

Regional anesthesia or a nerve block injection is used to treat a pronated forearm (Roberts et al., 2006). The sustained benefits and safety of injecting antispasmodic agents to manage spasticity and their efficacy for improving quality of extremity movement have been supported by many clinical studies (Hurvitz et al., 2003; Kawamura et al., 2007; Lowe et al., 2007). These injections should be placed close to the region where the motor entry point (MEP) is most densely distributed to achieve maximal effects.
The location of the MEP changes due to upper limb spasticity in a pronated forearm, so investigating the location of the MEP in a pronated state is necessary to enhance the effect.

Methods including ultrasound-guided brachial plexus blockage and peripheral nerve stimulation have been used to guide needle location. However, a blind injection is needed in some cases, which enhances the importance of these studies.

In this study, we investigated changes in median nerve location to innervate the PT based on pronation and normal positions. The comparison shows the proper location for applying regional anesthesia to achieve median nerve block on the PT when a pronated forearm is spastic.

* Department of Neurosurgery, CHA Gumi Medical Center, CHA University, Pocheon, Korea.

**** Department of Anatomy, College of Medicine, Konyang University of Korea, Daejeon, Korea.

***** Department of Anatomy, College of Medicine, Korea University, Seoul, Korea.

This research was supported by basic science research program through the national research foundation of Korea (NRF) funded by the Ministry of Education, Science and Technology (NO. 2014R1A1A1006195) 


\section{MATERIAL AND METHOD}

Thirty fresh specimens from 15 adult Korean cadavers (10 males and five females; age range, 53-91 years) were examined. Cases with pathological changes or leg trauma were excluded.

Dissection: An incision was made $3 \mathrm{~cm}$ above of the medial epicondyle of the humerus to $2 \mathrm{~cm}$ below the elbow crease. After removing the skin around the elbow region, the nerve branch innervating the PT muscle was carefully exposed, and the MEP was indicated using a pin. The MEP was located measured based on forearm movement (Fig. 1).

Measurements: We used some bony landmarks, such as the most prominent point of the medial (MEH) and lateral epicondyles of the humerus (LEH) and the prominent point of the styloid process of the ulna (SPU) and radius (SPR). Two horizontal lines connected the MEH and LEH ( $\mathrm{x}$ coordinate) and the SPU and SPR. Then, a vertical line was made to define the y-coordinate connected to the midpoint of each of the two horizontal lines. The measurements are explained in Figure 2.

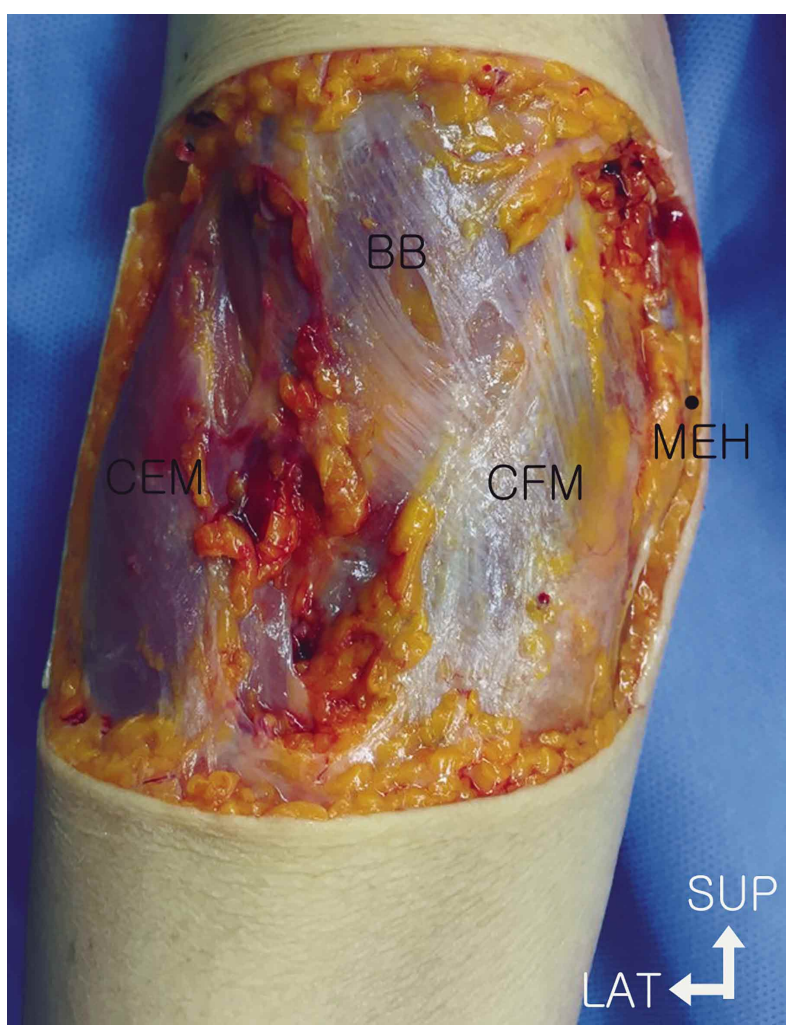

Fig. 1. Dissected elbow region with intact deep fascia. BB, biceps brachii; CEM, common extensor muscles; CFM, common flexor muscles; MEH: medial epicondyle of the humerus; SUP, superior; LAT, lateral.
The MEP for the PT was examined using digital calipers (Mitutoyo, Tokyo, Japan). The variables measured were:

1. Length of the reference line (from MEH to LEH) with the forearm in the normal position.

2. Length of the reference line (from SPU to SPR) with the forearm in the normal position.

3 . The vertical line in the normal position.

4. The vertical line in the pronated position.

5. Location of the MET to PT according to $\mathrm{x}$ and $\mathrm{y}$ coordinate of normal position.

6. Depth of \#5 variable.

7. Location of the MEP to the PT according to the $\mathrm{x}$ and $\mathrm{y}$ coordinates with the forearm in the pronated position.

8. Depth of variable \# 7.

All data was analyzed using SPSS ver. 17.0 software (SPSS Inc., Chicago, IL, USA). Comparisons between males and females were performed using the t-test. A p-value $<0.05$ was considered significant.

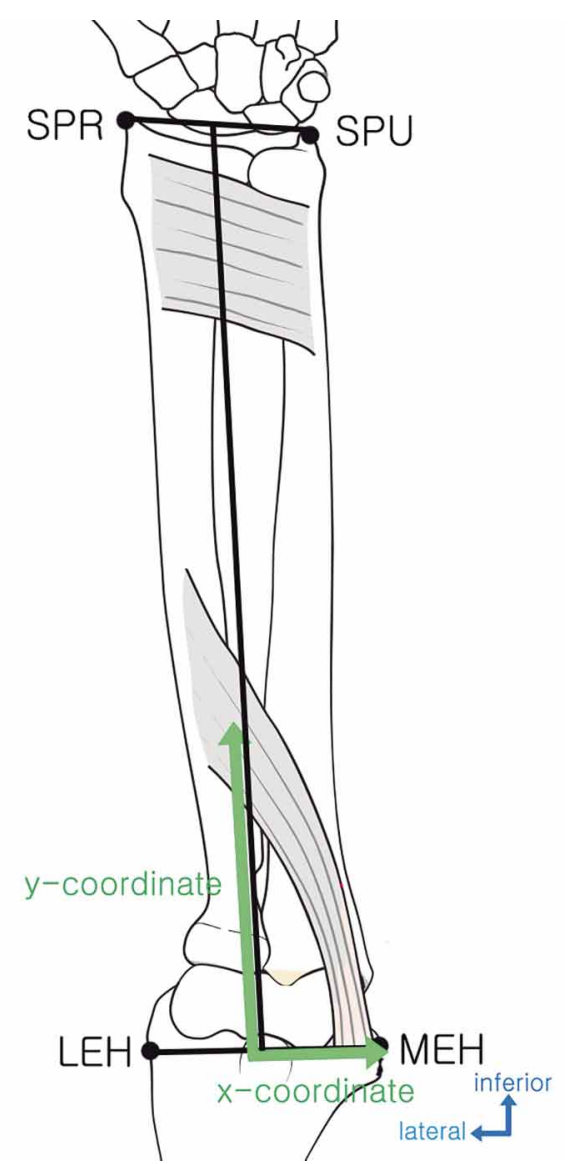

Fig. 2. Drawing showing the reference line from the epicondyle of the humerus to the styloid process of the radius. MEH: medial epicondyle of the humerus, LEH: lateral epicondyle of the humerus, SPR: styloid process of radius, SPU: styloid process of ulna. 


\section{RESULTS}

No significant differences were observed between males and females. The mean length of the reference line (from MEH to LEH) with the forearm in the normal position was $7.5 \pm 1.1 \mathrm{~cm}$ and the reference line (from SPU to SPR) for the normal position was $5.8 \pm 0.7 \mathrm{~cm}$. The vertical line for the normal position was $25.8 \pm 2.4 \mathrm{~cm}$ and the vertical line for the pronated position was $24.8 \pm 2.3 \mathrm{~cm}$.

The $\mathrm{x}$ and $\mathrm{y}$ coordinates of first MEP with forearm in the normal position were $1.6 \pm 0.6 \mathrm{~cm}$ and $2.8 \pm 1.3 \mathrm{~cm}$, respectively. The depth of the MEP was $1.5 \pm 0.3 \mathrm{~cm}$. The $\mathrm{x}$ and y coordinates of the second MEP were $1.3 \pm 0.3 \mathrm{~cm}$ and $4.7 \pm 1.7 \mathrm{~cm}$, respectively. The depth of the MEP was $1.4 \pm 0.2$ cm (Fig. 3, Fig. 4A).

The $\mathrm{x}$ and $\mathrm{y}$ coordinates of first MEP with forearm in the pronated position were $1.9 \pm 0.7 \mathrm{~cm}$ and $2.3 \pm 0.8 \mathrm{~cm}$, respectively. The depth of the MEP was $1.7 \pm 0.4 \mathrm{~cm}$. The $\mathrm{x}$ and y coordinates of the second MEP were $1.6 \pm 0.7 \mathrm{~cm}$ and $4.4 \pm 1.7 \mathrm{~cm}$ respectively. The depth of the MEP was $1.6 \pm 0.3$ cm (Fig. 3, Fig. 4B).

One or two nerves branched out from the median nerve. Only one branch was found in 20 cases $(66.7 \%)$, and two branches were found in 10 cases $(33.3 \%)$.

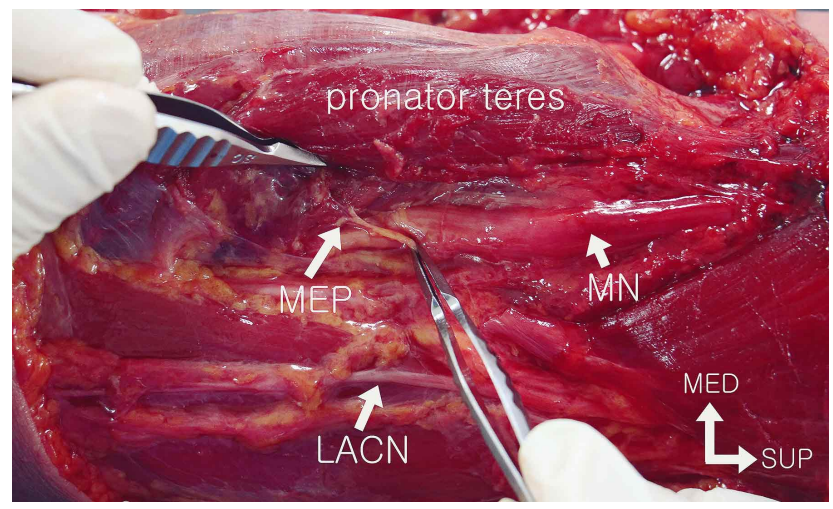

Fig. 3. Dissected left forearm showing the nerve branch and motor entry point innervating the pronator teres muscle. MEP, motor entry point; MN, median nerve; LACN, lateral antebrachial cutaneous nerve; MED, medial; SUP, superior.

\section{DISCUSSION}

Roberts et al. reported that all 20 embalmed cadavers had two motor branches, as found previously in other studies (Canovas et al., 1998; Safwat \& Abdel-Meguid, 2007). In
A
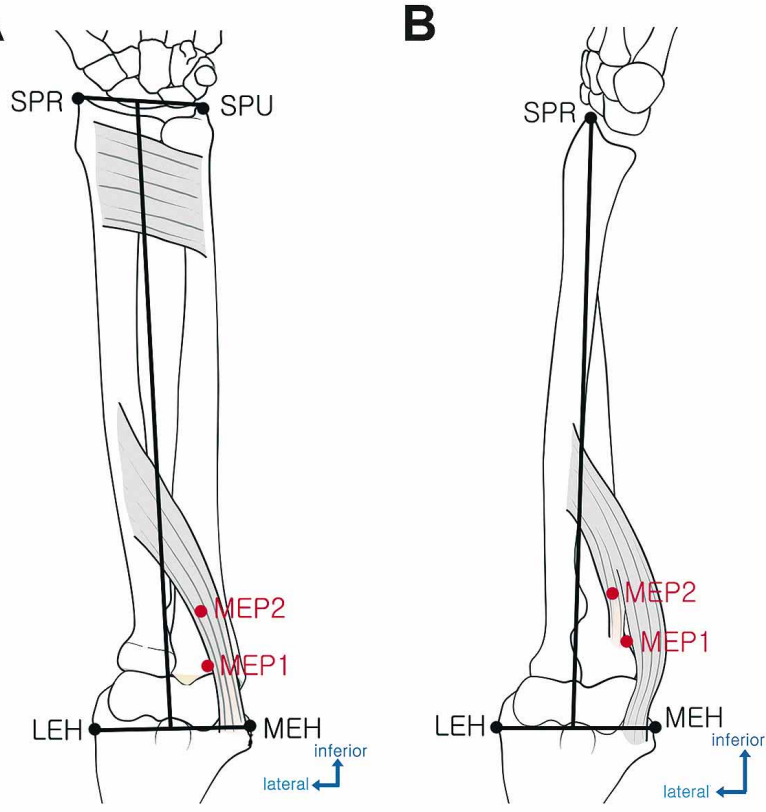

Fig. 4. The location of motor entry point (MEP) of pronator teres in normal position (A) and pronated position (B). MEH: medial epicondyle of the humerus, LEH: lateral epicondyle of the humerus, SPR: styloid process of radius, SPU: styloid process of ulna, MEP1: the first motor entry point, MEP2: the second motor entry point.

contrast, another study found one or two median nerve branches to the PT (Tubbs et al., 2011). We discovered that the PT was supplied by one or two motor nerve branches; however, more cases had one motor branch than two. Some authors have reported the motor point, which is the location where the nerve enters the muscle belly (Lee et al., 2011). We considered that of more than one motor point was found in $<0.5 \mathrm{~cm}$ area, it was considered one motor point because of spreading agent. This is the most effective method in the clinical field.

In the normal and pronated position, the primary MEP in almost all of our cases regardless of the position of the forearm was located at 8-9\% on the y-coordinate from the epicondyle as the starting point, except in six cases when the $y$-coordinate values were converted to percentages. The secondary MEP was located at $18 \%$; however, $66.7 \%$ of all cases had one motor branch, so the $8-9 \%$ area mentioned earlier provided a better result.

We investigated differences in the MEP based on forearm movement. The locations differed by $0.3 \mathrm{~cm}$ based on movement of the nerve branch, and the depths were 0.2 $\mathrm{cm}$. If a patient is rigid with spasticity, the injection is made in the pronated condition. Thus, our results of the pronated position will be helpful in the clinical field. 


\section{ACKNOWLEDGEMENTS}

We thank for donated bodies to our medical school.

KWON, S.; JEONG, Y.; LEE, N. S.; HAN, S. Y.; UHM, C. S.; KIM, D. \& LEE, J. H. Cambio de posición del nervio mediano evaluado mediante disección cadavérica blanda según el movimiento del antebrazo. Int. J. Morphol., 34(2):759-762, 2016.

RESUMEN: El objetivo fue examinar el cambio de posición del nervio mediano de acuerdo con el movimiento del antebrazo. Se examinaron 30 muestras frescas de 15 cadáveres adultos coreanos ( 10 hombres y 5 mujeres) con edades entre 53-91 años. Se midió el punto de entrada motor de acuerdo con las posiciones normales y pronación del antebrazo. Las coordenadas $\mathrm{X}$ e Y del primer punto de entrada motor (PEM) en la posición normal fueron de $1,6 \pm 0,6 \mathrm{~cm}$ y $2,8 \pm 1,3 \mathrm{~cm}$, respectivamente. La profundidad del PEM fue de 1,5 $\pm 0,3 \mathrm{~cm}$. Las coordenadas $\mathrm{X}$ e $\mathrm{Y}$ del segundo $P E M$ fueron $1,3 \pm 0,3 \mathrm{~cm}$ y $4,7 \pm 1,7 \mathrm{~cm}$, respectivamente. La profundidad del PEM fue $1,4 \pm 0,2 \mathrm{~cm}$. Las coordenadas X e Y del primer PEM del antebrazo en posición de pronación fueron $1,9 \pm 0,7 \mathrm{~cm}$ y $2,3 \pm 0,8 \mathrm{~cm}$, respectivamente. La profundidad del PEM fue $1,7 \pm 0,4 \mathrm{~cm}$. Las coordenadas $\mathrm{X}$ e $\mathrm{Y}$ del segundo PEM fueron $1,6 \pm 0,7 \mathrm{~cm}$ y $4,4 \pm 1,7 \mathrm{~cm}$, respectivamente. La profundidad del PEM fue 1,6 $\pm 0,3 \mathrm{~cm}$. Las diferencias en las ubicaciones de acuerdo con el movimiento del ramo nervioso fueron de 0,3 $\mathrm{cm}$, y las profundidades fueron de $0,2 \mathrm{~cm}$. Los resultados de la posición de pronación de este estudio serán útiles en trabajos clínicos.

PALABRAS CLAVE: Anatomía; Nervio mediano; Movimiento del antebrazo; Punto de entrada motor; Inyección.

\section{REFERENCES}

Canovas, F.; Mouilleron, P. \& Bonnel, F. Biometry of the muscular branches of the median nerve to the forearm. Clin. Anat., 11(4):239-45, 1998

Hurvitz, E. A.; Conti, G. E. \& Brown, S. H. Changes in movement characteristics of the spastic upper extremity after botulinum toxin injection. Arch. Phys. Med. Rehabil., 84(3):444-54, 2003.

Kawamura, A.; Campbell, K.; Lam-Damji, S. \& Fehlings, D. A randomized controlled trial comparing botulinum toxin A dosage in the upper extremity of children with spasticity. Dev. Med. Child. Neurol., 49(5):331-7, 2007.

Lee, J. H.; Lee, B. N.; An, X.; Chung, R. H.; Kwon, S. O. \& Han, S.H. Anatomic localization of motor entry point of superficial peroneal nerve to peroneus longus and brevis muscles. Clin. Anat., 24(2):232-6, 2011.
Lowe, K.; Novak, I. \& Cusick, A. Repeat injection of botulinum toxin $\mathrm{A}$ is safe and effective for upper limb movement and function in children with cerebral palsy. Dev. Med. Child. Neurol., 49(11):823-9, 2007.

Roberts, C.; Crystal, R. \& Eastwood, D. M. Optimal injection points for the neuromuscular blockade of forearm flexor muscles: a cadaveric study. J. Pediatr. Orthop. B., 15(5):351-5, 2006.

Safwat, M. D. \& Abdel-Meguid, E. M. Distribution of terminal nerve entry points to the flexor and extensor groups of forearm muscles: an anatomical study. Folia Morphol. (Warsz), 66(2):83-93, 2007.

Tubbs, R. S.; Beckman, J. M.; Loukas, M.; Shoja, M. M. \& CohenGadol, A. A. Median nerve branches to the pronator teres: cadaveric study with potential use in neurotization procedures to the radial nerve at the elbow. J. Neurosurg., 114(1):253-5, 2011.

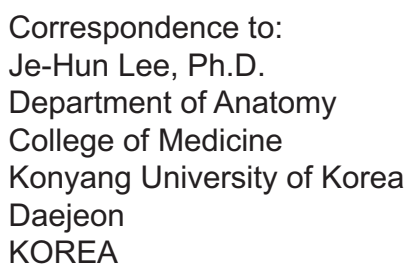

Email: leejehun@konyang.ac.kr

Received: 18-09-2015

Accepted: 12-05-2016 